\title{
Letter to the Editor
}

\section{Hip Resurfacing Does Not Improve Proprioception Compared With THA}

\author{
Julien Girard MD, PhD
}

Received: 18 June 2013/Accepted: 24 July 2013/Published online: 3 August 2013

(C) The Association of Bone and Joint Surgeons(B) 2013

\section{To the editor,}

I read the paper, "Hip Resurfacing Does Not Improve Proprioception Compared With THA" by Larkin et al. [4] with great interest. The authors stated that dynamic posturography is the best surrogate for measuring proprioception, offering only one reference to validate this data [1]. But in the current study, the authors concluded that the "diagnosis of balance disorders using dynamic posturography is best achieved using measures of trunk control following pure toe-up rotational perturbations tested under eyes-closed conditions" [4]. It is crucial to analyze articular proprioception; a complete evaluation of proprioception cannot be limited to dynamic postural stability.

Proprioception is defined by the sensation of joint motion (kinesthesia) and joint position (joint position sense) [2, 3].

(Re: Larkin B, Nyazee H, Motley J, Nunley RM, Clohisy JC, Barrack RL. Hip Resurfacing Does Not Improve Proprioception Compared With THA. [published online ahead of print June 1, 2013]. Clin Orthop Relat Res. DOI: 10.1007/s11999-013-3082-8).

The author certifies that he, or any members of his immediate family, has no funding or commercial associations (eg, consultancies, stock ownership, equity interest, patent/licensing arrangements, etc) that might pose a conflict of interest in connection with the submitted article.

All ICMJE Conflict of Interest Forms for authors and Clinical Orthopaedics and Related Research editors and board members are on file with the publication and can be viewed on request.

The opinions expressed are those of the writers, and do not reflect the opinion or policy of $C O R R^{\mathbb{R}}$ or the Association of Bone and Joint Surgeons ${ }^{\circledR}$.

J. Girard $(\square)$

Department of Orthopaedic Surgery, Hospital R. Salengro,

2 Avenue Oscar Lambret, Lille, Nord Pas de Calais 59037,

France

e-mail: j_girard_lille@yahoo.fr
Joint position sense is determined by measuring the accuracy of joint angle replication. In the paper by Larkin et al., the authors did not offer results about the pre and postoperative range of hip motion. Kinesthesia is closely correlated with hand-eye coordination. As discussed by Allum et al. [1], the only way to analyze proprioception is by performing a dynamic test with eyes-opened and eyesclosed conditions. The data and the conclusions would have been more relevant with a single- and double-limb analysis with eyes-opened and eyes-closed conditions.

On the other hand, the disruption of muscle could lead to partial desafferentation of the joint and surrounding musculature, according to the type of surgical approach. Posterolateral or anterior approaches result in different lesions of cutaneous and articular proprioceptors. The authors did not specify the surgical approach used and have not confirmed that the same approach was used for all the cases.

As discussed above, proprioception is a very complex system with a multimodal complex of sensations, including visual and vestibular inputs and/or sensory complex. For example, the authors did not consider the dynamic stabilometric effect, different hip motor patterns, or dynamic analysis of the foot pressure center, which are the important parts of articular proprioception [5, 6]. Additionally, the authors discussed proprioception without any specification about the type of proprioception used: hip proprioception, lower limb proprioception, articular proprioception, or conscious proprioception.

The authors could only analyze and discuss the dynamic postural stability of the lower limb after hip arthroplasty. I feel that in the absence of evidence of global comprehension on proprioception, the conclusions of this study should be treated with caution. From my point of view, these results are not in line with a full definition of "proprioception." 


\section{References}

1. Allum JH, Bloem BR, Carpenter MG, Honegger F. Differential diagnosis of proprioceptive and vestibular deficits using dynamic support-surface posturography. Gait Posture. 2001;14: 217-226.

2. Collins M, Lavigne M, Girard J, Vendittoli PA. Joint perception after hip or knee replacement surgery. Orthop Traumatol Surg Res. 2012;98:275-280.

3. Ishii $\mathrm{Y}$, Tojo $\mathrm{T}$, Terajima $\mathrm{K}$, Terashima $\mathrm{S}$, Bechtold JE. Intracapsular components do not change hip proprioception. $J$ Bone Joint Surg Br. 1999;81:345-348.
4. Larkin B, Nyazee H, Motley J, Nunley RM, Clohisy JC, Barrack RL. Hip Resurfacing Does Not Improve Proprioception Compared With THA. [published online ahead of print June 1, 2013]. Clin Orthop Relat Res. DOI: 10.1007/s11999-013-3082-8.

5. Lavigne M, Therrien M, Nantel J, Prince F, Laffosse JM, Girard J, Vendittoli PA. Biomechanical and clinical characteristics after large diameter total hip prosthesis versus resurfacing. J Bone Joint Surg Br. 2011;93:522-523.

6. Szymanski C, Thouvarecq R, Dujardin F, Migaud H, Maynou C, Girard J. Functional performance after hip resurfacing or total hip replacement: a comparative assessment with non-operated subjects. Orthop Traumatol Surg Res. 2012;98:1-7. 